\title{
Dental caries prevalence and its association with fluoride level in drinking water in Sana'a, Yemen
}

\author{
Ameen Abdullah Al-Akwa ${ }^{1}$, Sadeq Ali Al-Maweri²,3
}

Correspondence: Dr. Sadeq Ali Al-Maweri

Email: sadali05@hotmail.com

\author{
'Department of Preventive and Pediatric Dentistry, \\ Sana'a University, Sana'a, Yemen, \\ 'Department of Oral Medicine and Diagnosis, \\ Sana'a University, Sana'a, Yemen, \\ ${ }^{3}$ Department of Oral Medicine and Diagnostic Sciences, \\ Alfarabi Colleges, Riyadh, Saudi Arabia
}

\section{ABSTRACT}

Objectives: Dental caries is the most prevalent chronic condition affecting schoolchildren worldwide. This study is aimed to assess the prevalence of dental caries among schoolchildren in urban and rural districts of Sana'a governorate, Yemen, and to investigate the correlation between caries experience and level of fluoride in drinking water, age, gender, and residence. Materials and Methods: This school-based survey involved 17,599 schoolchildren (aged 6-12 years), of whom 9623 were boys and 7976 were girls. We used decay-missing-filled teeth/decay-filled teeth (DMFT/dft) indices to evaluate dental caries experience. In addition, fluoride concentration in drinking water was investigated. Results: Around $67.6 \%$ of children had dental caries. Children residing in urban districts had significantly higher mean scores of DMFT/dft than those in rural areas $(P<0.05)$. A significant negative correlation between caries experience and fluoride level was found $(P<0.05)$, with the lowest dft/DMFT scores at the optimum fluoride level of $0.61-2 \mathrm{ppm}$ and the highest at two extremes, $0.0-0.4 \mathrm{ppm}$ and $>2 \mathrm{ppm}$. Conclusion: This survey found a very high prevalence of caries among schoolchildren in Yemen. There was also an inverse relation between dental caries experience and fluoride levels.

Key words: Dental caries, fluoride level, prevalence, schoolchildren, Yemen

\section{INTRODUCTION}

Dental caries is a common infectious chronic disease that negatively affects the quality of life, causing pain, chronic infections, and sleep disturbance. Despite significant advances in oral health, dental caries is still a major public health issue worldwide, being the most prevalent chronic condition among schoolchildren, and highly elevated even in developed countries. ${ }^{[1]}$ Dental caries prevalence is influenced by many factors, such as age, gender, ethnic group, dietary habits, and oral hygiene habits. ${ }^{[1]}$

\begin{tabular}{|l|l|}
\hline \multicolumn{2}{|c|}{ Access this article online } \\
\hline Quick Response Code: \\
\hline
\end{tabular}

Although dental caries prevalence in children has declined markedly over the past few decades in the industrial countries, the disease is still a major problem for both adults and children in less developed countries. ${ }^{[1]}$ The declining trend in caries prevalence in developed countries has been attributed to the use of fluoride in different forms, diet control, and other preventive measures. On the other hand, an increase in dental caries in developing countries has resulted from unhealthy dietary habits, combined with the limited use of fluoride and poor access to oral health services. ${ }^{[1]}$

This is an open access article distributed under the terms of the Creative Commons Attribution-NonCommercial-ShareAlike 3.0 License, which allows others to remix, tweak, and build upon the work non-commercially, as long as the author is credited and the new creations are licensed under the identical terms.

For reprints contact: reprints@medknow.com

How to cite this article: Al-Akwa AA, Al-Maweri SA. Dental caries prevalence and its association with fluoride level in drinking water in Sana'a, Yemen. Eur J Dent 2018;12:15-20.

DOI: 10.4103/ejd.ejd_187_17 
The negative relationship between the fluoride concentration of drinking water and dental caries has been established in the literature, and fluoridation of drinking water for caries prevention is recommended by health authorities. ${ }^{[2,3]}$ The main action of fluorides in reducing dental caries is through the ionic exchange between the enamel surface and the fluoride. This reaction will change the surface calcium hydroxyapatite of enamel to calcium fluoroapatite, which is more resistant to dissolution in acids. ${ }^{[4]}$

As with other developing countries, dental caries is still a major health problem in Yemen, and its prevalence is still on the rise. ${ }^{[1,5]}$ The change in lifestyle of Yemenis combined with poor oral hygiene and the lack of government health services and preventive policies are the main contributing factors to this trend. ${ }^{[1]}$ Data on dental caries are still scarce in Yemen, with only a very few studies have evaluated the incidence of dental caries among schoolchildren, and most of these studies were limited to schoolchildren in urban areas; none have evaluated dental caries among schoolchildren in rural areas. ${ }^{[5,6]}$ Moreover, there has been no data as yet relating dental caries to various fluoride levels in Yemen. The availability of such data is of paramount importance in planning dental health programs and public health services, the evaluation of interventions, and following up on disease trends. Therefore, the purposes of this study were to assess the prevalence of dental caries among Yemeni schoolchildren attending public schools in different regions of Sana'a governorate and to relate the outcomes to fluoride levels in drinking water, age, gender, and residence.

\section{MATERIALS AND METHODS}

Yemen is the second-largest country on the Arabian Peninsula, having a total area of $527,970 \mathrm{~km}^{2}$ and a total population of 24 million, with $50 \%$ of the population being under 15 years. Sana' a governorate, the Yemeni capital, is located in the central part of the country, with an area of 14,204 km. Sana'a is divided into two main parts. First, the capital secretariat (Amanet Al-Aasema in Arabic), which is the only urban area in the governorate, is the capital of the governorate, as well as the national capital. The capital secretariat is further divided into six administrative districts of varying socioeconomic standards of living. Second is Sana' a province, which includes 16 rural directorates. These directorates belong administratively to the capital city, and each is divided into 3-5 districts. Except with one district, all of these directories are rural areas.

This school-based survey was conducted in Sana'a governorate during the period between December 2011 and June 2012. The study population consisted of 6-12-year-old children attending public primary schools (from Grades 1-6) for boys and girls in rural and urban areas of Sana'a governorate. The stratified random sampling technique was adopted for this study. As noted above, each directorate consists of 3-6 administrative districts, making a total of 73 districts. In each district, the largest primary school was selected, and thus, a total of 73 schools were included in the study [Table 1a]. These schools include classes with mixed genders. In each of the selected schools, the first classroom was chosen

\begin{tabular}{|c|c|c|c|c|c|}
\hline Directorate & Residence & Number of districts & Number of schools & Number of students & Mean fluoride level \\
\hline Hamadan & Rural & 5 & 5 & 1037 & 0.446 \\
\hline BaniMatar & Rural & 4 & 4 & 991 & 0.491 \\
\hline Arhab & Rural & 4 & 4 & 1050 & 0.501 \\
\hline Manakhah & Rural & 4 & 4 & 997 & 0.534 \\
\hline Secretariat & Urban & 6 & 6 & 1360 & 0.538 \\
\hline Taial & Rural & 4 & 4 & 978 & 0.568 \\
\hline Al-Haimah Da & Rural $^{*}$ & 4 & 4 & 1133 & 0.635 \\
\hline BaniThabian & Rural & 4 & 4 & 1072 & 0.659 \\
\hline Nihm & Rural & 4 & 4 & 1013 & 0.747 \\
\hline Bani Hashish & Rural & 4 & 4 & 1043 & 0.808 \\
\hline Jehana & Rural & 4 & 4 & 1013 & 1.262 \\
\hline Al-Haimah Kh & Rural & 4 & 4 & 988 & 1.708 \\
\hline Bilad Al-Roos & Rural & 6 & 6 & 1134 & 1.726 \\
\hline Safan & Rural & 4 & 4 & 1004 & 1.983 \\
\hline Khawlan & Rural & 3 & 3 & 900 & 2.088 \\
\hline Al-Hesn & Rural & 4 & 4 & 1003 & 2.457 \\
\hline Sanhan & Rural & 5 & 5 & 950 & 5.023 \\
\hline
\end{tabular}


(usually alphabetically listed as class A). According to availability, around 40-60 students from each grade were randomly selected for the study, thus giving a total number of about 250 students from each school being examined. The final sample comprised 17,599 students ( 9623 boys and 7976 girls). Urban areas were represented in six areas of Amanet Al-Aasema, in addition to one area in the center of Al-Hema district, making a total of 1596 students, whereas the rural areas were represented by 16 directorates (except one district), making a total of 16,003 students.

The study was approved by the Research and Ethical Committee of the Faculty of Medicine and Health Sciences, Sana'a University, and informed written consent was obtained from parents or guardians before the students were included in the study.

The examination was conducted according to the World Health Organization (WHO) criteria. ${ }^{[7]}$ The students were examined in their classes while seated on an ordinary chair under natural daylight using sterilized packaged hand instruments. Dental caries was assessed using decay-filled teeth (dft) for primary teeth and the decay-missing-filled teeth (DMFT) index for permanent teeth. All clinical examinations were carried out by four calibrated examiners, each with an assistant recording the observations. Clinical examination was done using sufficient numbers of sterilized instruments, such as mouth mirrors, probes, and tweezers. Before recording dental caries status, the teeth were wiped off using cotton to remove food debris. Before undergoing a dental examination, demographic information, such as age, gender, and residence, was obtained for each student.

Calibration of the examiners was carried out at the Department of Pediatrics Dentistry at Sana'a University. Examiners were calibrated for diagnosis of dental caries with a reference examiner; this was taken as the "gold standard." Initially, this calibration covered the theory of diagnostic criteria and common diagnostic problems, using images of all different clinical conditions of teeth with and without caries. The second phase started with every examiner examining 20 children twice, with the same children also examined once by the reference examiner. Results were then analyzed, and disagreements were discussed. Nonstandard examiners were asked to examine 10 new children and were again compared with the standard examiners until they reached an agreement, with intraexaminer and interexaminer reliability test of Kappa reached at least $80 \%$.

\section{Assessment of fluoride levels}

Every administrative district in the urban areas of Sana'a (the capital secretariat) is provided by its own separate system of communal water supply network. The water supply is provided from a main reservoir that collects water from several artesian wells. In the rural areas, on the other hand, the source of water is mainly from ground wells. Water samples of $500 \mathrm{~mL}$ of tap water were taken after allowing the water to flow for $2 \mathrm{~min}$ into polythene bottles previously washed with distilled water, dried in air, and rinsed with water from which the samples were collected. Where there was a communal water supply, samples were obtained from the central water tank and from the terminal school water taps. In small towns and villages in each directorate, the water samples were collected from some of the drinking wells and reservoirs in those areas. In each directorate, at least eight water samples were collected (four from sources and four from terminal water taps at the schools), representing the water drank by the residents of the corresponding districts. This amounted to total water samples of 146. Samples of water were analyzed for fluoride concentration at the central laboratory, Ministry of Water by using an F ion selective electrode using the direct calibration method. Direct calibration is a simple procedure for measuring a large number of samples. Only one reading is required for each sample.

\section{Statistical analysis}

Descriptive data were presented as frequencies and percentages, and the outcomes were analyzed using Chi-square test. The quantitative data were presented as means and standard deviations; these outcomes were checked for normal distribution using the Kolmogorov-Smirnov test. As these variables were not normally distributed, data were analyzed using the nonparametric Kruskal-Wallis and Mann-Whitney tests, as appropriate. The value of $P<0.05$ was considered as statistically significant.

\section{RESULTS}

A total of 17,599 schoolchildren participated in the study, of whom 9,623 (54.7\%) were boys and $7,976(45.3 \%)$ were girls. The mean age was $8.8 \pm 18$ years (range: $6-12$ ). Around $25.5 \%$ were in the $6-7$ years age group, $39.5 \%$ in the $8-9$ years age group, and $34.8 \%$ in the $10-12$ years age group. Most of the children $(90.9 \%)$ resided in rural areas [Table $1 \mathrm{~b}$ ].

The overall prevalence of dental caries was $67.6 \%$. Children residing in urban areas showed the 
Al-Akwa and Al-Maweri: Dental caries in relation to fluoride level

\begin{tabular}{|c|c|c|c|c|c|c|}
\hline \multirow[t]{2}{*}{ Age group (years) } & \multicolumn{3}{|c|}{ Gender } & \multicolumn{3}{|c|}{ Residence } \\
\hline & Boys, $n(\%)$ & Girls, $n(\%)$ & Total, $n(\%)$ & Rural, $n(\%)$ & Urban, $\boldsymbol{n}(\%)$ & Total, $\boldsymbol{n}(\%)$ \\
\hline $6-7$ & $2531(26.3)$ & $1978(24.8)$ & $4509(25.7)$ & $3984(24.9)$ & $525(32.9)$ & $4509(25.7)$ \\
\hline $8-9$ & $3724(38.7)$ & $3231(40.5)$ & 6955 (39.5) & $6333(39.6)$ & $622(39)$ & 6955 (39.5) \\
\hline $10-12$ & $3368(35)$ & $2767(34.7)$ & $6135(34.8)$ & $5686(35.5)$ & $449(28.1)$ & $6135(34.8)$ \\
\hline Total & $9623(54.7)$ & $7976(45.3)$ & $17,599(100)$ & $16,003(90.9)$ & $1596(9.1)$ & $17,599(100)$ \\
\hline
\end{tabular}

significantly higher prevalence of dental caries (85.2\%) compared to children residing in rural areas $(65.9 \%$; $P<0.001)$ [Table 2].

Table 3 shows caries experience indices in primary $\mathrm{dft}$ and permanent dentitions dft DMFT according to gender, and residence. Children in urban areas had significantly higher DMFT and dft scores (1.25 and 3.14, respectively) than children in rural areas ( 0.83 and 2.12 , respectively). On the other hand, there were no significant differences in the mean DMFT/dft scores between boys and girls $(P>0.05)$. Decayed teeth $(d / D)$ were the major components of both $\mathrm{dft}$ and DMFT indices for all age groups [Table 3].

The concentration of $\mathrm{F}$ in the village water was found to vary widely from $0.131 \mathrm{ppm}$ to $13.1 \mathrm{ppm}$. The lowest mean of fluoride was observed in Hamdan directorate $(0.45 \mathrm{ppm})$, whereas thehighest wasinSanhan and Banibahlol directorate (5.02 ppm); [Table 1a].

There was a significant negative correlation between caries experience and fluoride level $(P<0.05)$, with the lowest dft/DMFT scores at the optimum fluoride level of $0.61-2 \mathrm{ppm}$ and the highest at two extremes, 0.0-0.4 ppm and >2 ppm [Table 4].

\section{DISCUSSION}

To the best of our knowledge, this is the first large-scale study to explore these issues among schoolchildren in Yemen. The obtained data will help in the planning of future preventive and restorative dental services nationwide.

The prevalence of dental caries in the present study was $67.6 \%$. This high rate is similar to recent studies in neighboring and other developing countries. ${ }^{[8-14]}$ However, this rate contrasts hugely with trends in many industrialized countries. ${ }^{[15]}$ Moreover, the prevalence of caries among 6-7-year-old children in the present study (68.9\%) is much higher than the goals recommended by the $\mathrm{WHO}$ and the Federation of Dentistry International of $<50 \%$ caries-free children. ${ }^{[16]}$ Such findings emphasize the urgent need for effective

\begin{tabular}{|c|c|c|}
\hline Variables & $n(\%)$ & $P$ \\
\hline \multicolumn{3}{|l|}{ Gender } \\
\hline Boys & $6484(67.4)$ & 0.694 \\
\hline Girls & $5421(67.9)$ & \\
\hline \multicolumn{3}{|l|}{$\begin{array}{l}\text { Age } \\
\text { group (years) }\end{array}$} \\
\hline $6-7$ & 3108 (68.9) & 0.105 \\
\hline $8-9$ & $4628(66.5)$ & \\
\hline $10-12$ & $4169(68)$ & \\
\hline \multicolumn{3}{|l|}{ Residence } \\
\hline Rural area & $10,544(65.9)$ & 0.001 \\
\hline Urban area & $1361(85.2)$ & \\
\hline Total & $11,905(67.6)$ & \\
\hline
\end{tabular}

restorative and preventive anti-caries measures at the national level in Yemen.

A striking finding from this study was that the decayed teeth $(\mathrm{dt}, \mathrm{DT})$ constituted the major fraction of dft/DMFT scores, with a very low-filled component [Table 3], revealing a high rate of unmet treatment needs. This finding supports previous studies conducted in urban areas of Sana'a. ${ }^{[5,6]}$ As in other studies in Yemen, only a few extractions and a limited number of restorations were observed. These findings also support previous findings from many neighboring Arab countries, which reported that over $90 \%$ of dental caries in schoolchildren are untreated. ${ }^{[9,12,13,17]}$ This highly reflects the minimal amount of dental treatment received by the children, which can be attributable to poor oral health knowledge and/or attitude, cost of treatment, low priority given to dental care in society, and reduced access to public health facilities. It is worth noting that, in Yemen, like most developing countries, there is no health insurance system, and the provision of oral health services in the country is primarily private and so expensive that most families of lower and even middle socioeconomic status cannot afford them. Thus, dental treatment becomes a burden for most of the population in a country where $45 \%$ of the population is under the poverty line. 


\begin{tabular}{|c|c|c|c|c|c|c|c|}
\hline & dft & d & $f$ & DMFT & D & $M$ & $F$ \\
\hline \multicolumn{8}{|l|}{ Gender } \\
\hline Male & $2.22 \pm 2.21$ & $2.21 \pm 2.23$ & $0.22 \pm 0.20$ & $0.87 \pm 1.58$ & $0.86 \pm 1.56$ & $0.01 \pm 0.15$ & $0.01 \pm 0.14$ \\
\hline Female & $2.23 \pm 2.20$ & $2.20 \pm 2.20$ & $0.01 \pm 0.16$ & $0.88 \pm 1.52$ & $0.86 \pm 1.49$ & $0.01 \pm 0.13$ & $0.01 \pm 0.16$ \\
\hline$P$ & 0.916 & 0.933 & 0.119 & 0.201 & 0.400 & 0.482 & 0.112 \\
\hline \multicolumn{8}{|l|}{ Residence } \\
\hline Rural & $2.12 \pm 2.18$ & $2.11 \pm 2.18$ & $0.01 \pm 0.17$ & $0.83 \pm 1.54$ & $0.82 \pm 1.52$ & $0.01 \pm 0.13$ & $0.01 \pm 0.13$ \\
\hline Urban & $3.14 \pm 2.37$ & $3.10 \pm 2.36$ & $0.04 \pm 0.26$ & $1.25 \pm 1.57$ & $1.19 \pm 1.50$ & $0.03 \pm 0.21$ & $0.03 \pm 0.26$ \\
\hline$P^{\ddagger}$ & $<0.05$ & $<0.05$ & $<0.05$ & $<0.05$ & $<0.05$ & $<0.05$ & $<0.05$ \\
\hline
\end{tabular}

\begin{tabular}{|c|c|c|c|}
\hline \multirow[t]{2}{*}{ Fluoride level } & \multirow[t]{2}{*}{ Number of student } & \multicolumn{2}{|c|}{ Mean $\pm S D$} \\
\hline & & dft & DMFT \\
\hline $0.00-0.4$ ppm & 2703 & $2.64 \pm 2.32$ & $1.01 \pm 1.44$ \\
\hline 0.41-0.6 ppm & 3413 & $2.19 \pm 2.16$ & $0.74 \pm 1.30$ \\
\hline $0.61-1 \mathrm{ppm}$ & 7331 & $2.12 \pm 2.15$ & $0.68 \pm 1.27$ \\
\hline $1.1-2 \mathrm{ppm}$ & 2485 & $2.01 \pm 2.08$ & $0.68 \pm 1.28$ \\
\hline 2.1-3 ppm & 144 & $2.04 \pm 2.07$ & $0.74 \pm 1.45$ \\
\hline$>3$ ppm & 1523 & $2.31 \pm 2.58$ & $2.17 \pm 2.77$ \\
\hline$P^{\dagger}$ & & $<0.001^{*}$ & $<0.001^{*}$ \\
\hline
\end{tabular}

The present study showed significantly higher caries prevalence among children residing in urban areas $(85.2 \%)$ than in rural areas $(65.9 \%)$. The mean $\mathrm{dft}$ and DMFT were also significantly lower among children in rural areas, a finding consistent with many previous studies reported elsewhere. ${ }^{[18,19]}$ Such findings are attributed to higher consumption of high sugar-containing food and beverages and more snacks consumption between meals in the urban areas. ${ }^{[19]}$ Another finding to be highlighted is that children in rural areas had significantly fewer extracted and filled teeth compared to those in the urban areas. Other studies also reported very minimal restoration care in rural schoolchildren. ${ }^{[18,19]}$ This finding can be explained by the low number or even absolute absence of dental clinics in rural areas, poverty, limited financial and human resources, and costs of transport to major cities, combined with a lack of oral health awareness. ${ }^{[5,20,21]}$

The present study showed a wide variation of fluoride levels in drinking water, ranging from 0.131 to $13.1 \mathrm{ppm}$. The lowest mean of fluoride was observed in Hamdan directorate (0.45 ppm), whereas the highest was observed in Sanhan and Banibahlol directorate (5.02 ppm). This great variation in fluoride concentration can be explained by the difference in the source of drinking water in different areas, which depends on the nature of the geographical structures and on the rocks that contain high-fluoride compounds. ${ }^{[22]}$ The inverse relationship between fluoride level and caries experience found in the present study is well established in the literature. ${ }^{[11,23,24]}$ The present study found that the mean value of $\mathrm{dft}$ and DMFT decreased gradually with the increase in water fluoride level from 0 to $2 \mathrm{ppm}$, and then, they increased gradually with increasing water fluoride level (>2 ppm). This finding can be discussed on the basis that the increase of water fluoride levels near the standard recommended level of 0.5-1.5 ppm produces a desirable effect by decreasing dental caries experience with minimum risk of dental fluorosis. ${ }^{[1]}$ On the other hand, high fluoride levels above $2 \mathrm{ppm}$, as seen in many areas of our study, are usually associated with moderate-to-severe forms of fluorosis, which leads to structural changes of dental tissues that become hypoplastic and thus more susceptible to caries. ${ }^{[1]}$ This finding is in line with previous studies that reported the least caries experience in children residing in areas with optimum fluoride levels. ${ }^{[11,17,22]}$ All in all, the balance between the achievement of maximum protection against dental caries and the risk of development of fluorosis should be taken into consideration. ${ }^{[25]}$

One of the strengths of the present study lies in its large sample size. Nevertheless, this study has some limitations that should be taken into consideration. The main limitation is that this survey did not investigate other risk factors reportedly associated with caries, such as sugar intake, oral hygiene practices, dental visits, parents' level of education, and socioeconomic status. Furthermore, no information was obtained regarding children's exposure to fluoride from other sources, which could have an influence on dental caries experience observed in this investigation. Such information would have shed some light on the 
potential risk factors of caries among this population, and hence, future studies to investigate in depth the effects of various variables on caries experience among Yemeni schoolchildren are highly recommended. In addition, despite this huge sample size and the fact that study was carried out in the most populous and multicultural city of Sana' a, which included both rural and urban areas, the generalizability of the results to all Yemeni schoolchildren is questionable. Therefore, more future studies that would cover different regions of the country are required.

\section{CONCLUSION}

Findings revealed that schoolchildren in Yemen have a high prevalence of dental caries and a large amount of untreated carious teeth. Furthermore, similar to previous reports, we found an inverse relationship between caries experience and drinking water fluoride level. Given the high prevalence of dental caries and extensive unmet treatment need, more studies that investigate in depth the associated risk factors are highly warranted.

\section{Acknowledgment}

The authors would like to thank all participants.

\section{Financial support and sponsorship}

Nil.

\section{Conflicts of interest}

There are no conflicts of interest.

\section{REFERENCES}

1. Petersen PE, Bourgeois D, Ogawa H, Estupinan-Day S, Ndiaye C. The global burden of oral diseases and risks to oral health. Bull World Health Organ 2005;83:661-9.

2. Petersen PE, Lennon MA. Effective use of fluorides for the prevention of dental caries in the $21^{\text {st }}$ century: The WHO approach. Community Dent Oral Epidemiol 2004;32:319-21.

3. Marinho VC. Cochrane reviews of randomized trials of fluoride therapies for preventing dental caries. Eur Arch Paediatr Dent 2009;10:183-91.

4. Zimmer S, Jahn KR, Barthel CR. Recommendations for the use of fluoride in caries prevention. Oral Health Prev Dent 2003;1:45-51.

5. Al-Haddad KA, Al-Hebshi NN, Al-Ak'hali MS. Oral health status and treatment needs among school children in Sana'a city, Yemen. Int J Dent Hyg 2010;8:80-5.

6. Al-Maweri SA, Al-Soneidar WA, Halboub ES. Oral lesions and dental status among institutionalized orphans in Yemen: A matched case-control study. Contemp Clin Dent 2014;5:81-4.

7. World Health Organization. Oral Health Surveys: Basic Methods. $4^{\text {th }}$ ed. Geneva: World Health Organization; 1997.

8. Yabao RN, Duante CA, Velandria FV, Lucas M, Kassu A, Nakamori M, et al. Prevalence of dental caries and sugar consumption among 6-12-year-old schoolchildren in la Trinidad, Benguet, Philippines. Eur J Clin Nutr 2005;59:1429-38.

9. Ahmed NA, Astrøm AN, Skaug N, Petersen PE. Dental caries prevalence and risk factors among 12-year old schoolchildren from Baghdad, Iraq: A post-war survey. Int Dent J 2007;57:36-44.

10. Nurelhuda NM, Trovik TA, Ali RW, Ahmed MF. Oral health status of 12-year-old school children in Khartoum state, the Sudan; a school-based survey. BMC Oral Health 2009;9:15.

11. AlDosari AM, Akpata ES, Khan N. Associations among dental caries experience, fluorosis, and fluoride exposure from drinking water sources in Saudi Arabia. J Public Health Dent 2010;70:220-6.

12. Hashim R, Williams SM, Thomson WM, Awad MA. Caries prevalence and intra-oral pattern among young children in Ajman. Community Dent Health 2010;27:109-13.

13. Rajab LD, Petersen PE, Baqain Z, Bakaeen G. Oral health status among 6- and 12-year-old Jordanian schoolchildren. Oral Health Prev Dent 2014;12:99-107.

14. Schwendicke F, Doost F, Hopfenmüller W, Meyer-Lueckel H, Paris S. Dental caries, fluorosis, and oral health behavior of children from Herat, Afghanistan. Community Dent Oral Epidemiol 2015;43:521-31.

15. Weusmann I, Mahmoodi B, Azaripour A, Kordsmeyer K, Walter C, Willershausen $\mathrm{B}$, et al. Epidemiological investigation of caries prevalence in first grade school children in Rhineland-Palatinate, Germany. Head Face Med 2015;11:33.

16. Aggeryd T. Goals for oral health in the year 2000: Cooperation between WHO, FDI and the national dental associations. Int Dent J 1983;33:55-9.

17. Al Dosari AM, Wyne AH, Akpata ES, Khan NB. Caries prevalence and its relation to water fluoride levels among schoolchildren in central province of Saudi Arabia. Int Dent J 2004;54:424-8.

18. Gugushe TS, du Plessis JB. Regional urban-rural distribution of dental caries experience in Swaziland. SADJ 1998;53:409-12.

19. Bajomo AS, Rudolph MJ, Ogunbodede EO. Dental caries in six, 12 and 15 year old Venda children in South Africa. East Afr Med J 2004;81:236-43.

20. Al-Maweri SA, Al-Jamaei AA, Halboub ES, Al-Soneidar WA, Tarakji B, Alsalhani A, et al. Fissure sealants: Knowledge and practice of Yemeni dental practitioners. Eur J Dent 2016;10:234-8.

21. Al-Maweri SA, Zimmer S. Oral health survey of 6-14-year-old children with disabilities attending special schools Yemen. J Clin Pediatr Dent 2015;39:272-6.

22. Bårdsen A, Bjorvatn K, Selvig KA. Variability in fluoride content of subsurface water reservoirs. Acta Odontol Scand 1996;54:343-7.

23. Armfield JM. Public water fluoridation and dental health in New South Wales. Aust N Z J Public Health 2005;29:477-83.

24. Meyer-Lueckel H, Bitter K, Khorrami G, Kielbassa AM, Paris S. Relationship of caries and fluorosis in adolescents from high- and low-fluoride areas in Iran. Community Dent Health 2011;28:248-52.

25. Hosur MB, Puranik RS, Vanaki S, Puranik SR. Study of thyroid hormones free triiodothyronine (FT3), free thyroxine (FT4) and thyroid stimulating hormone (TSH) in subjects with dental fluorosis. Eur J Dent 2012;6:184-90. 